\title{
Stereochemistry of Free-Radical Polymerization of Bulky Vinyl Esters
}

\author{
Tamaki NaKano, Ken-ichi Makita, and Yoshio OKamoto
}

Department of Applied Chemistry, Graduate School of Engineering, Nagoya University, Furo-cho, Chikusa-ku, Nagoya 464-8603, Japan

(Received January 12, 1998)

\begin{abstract}
KEY WORDS Vinyl Acetate / Vinyl Pivalate / Vinyl Diphenylacetate / Vinyl Triphenylacetate / Poly(vinyl alcohol) / Free-Radical Polymerization / Tacticity /
\end{abstract}

Poly(vinyl alcohol) (PVA) is produced by hydrolysis (saponification) of poly(vinyl ester)s obtained by freeradical polymerization and is used for various applications. The properties of PVA are dependent on stereochemical structure of the main chain and higher syndiotacticity generally gives better physical properties. ${ }^{1}$ Syndiotactic specificity of vinyl ester polymerization is affected by the structure of vinyl ester monomers: vinyl pivalate (VPi) leads to higher syndiotactic specificity compared with vinyl acetate (VAc). ${ }^{2-5}$ The higher syndiotactic specificity of VPi polymerization is considered to be based on steric repulsion of the bulky $t$-butyl group in the side chain of the monomer. In the present study, vinyl diphenylacetate (VDPAc) and vinyl triphenylacetate (VTPAc), which are bulkier than VPi, were prepared and stereochemistry of free-radical polymerization was investigated. Copolymerization of the bulky monomers with VAc or VPi was also carried out.

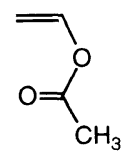

VAc<smiles>C=COC(=O)C(C)(C)C</smiles>

VPi
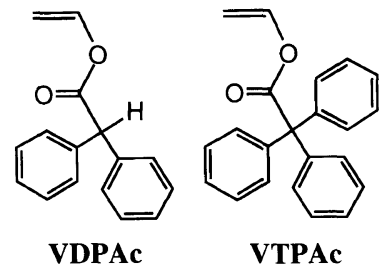

\section{EXPERIMENTAL}

\section{Materials}

VAc and VPi were washed with aqNaOH$(2 \%)$ and distilled. $\alpha, \alpha^{\prime}$-Azobisisobutyronitrile (AIBN) and benzoyl peroxide (BPO) were recrystallized from methanol. Diisopropyl peroxydicarbonate ((iso-PrOCOO $)_{2}$ ) was kindly provided by NOF Co. (Taketoyo-cho, Chita-gun, Aichi 470-23, Japan) and used as toluene solution $(0.309 \mathrm{M}) . N, N$-Dimethylaniline (DMA) was purified by distillation. The other reagents were purified by usual methods.

\section{Synthesis of VDPAc $c^{6}$}

VDPAc was synthesized by a published method ${ }^{6}$ with modifications. In a 500-ml flask, diphenylacetic acid ( $20 \mathrm{~g}$, $0.094 \mathrm{~mol})$ was dissolved in vinyl acetate $(110 \mathrm{ml}$, $1.19 \mathrm{~mol})$ and $\mathrm{HgSO}_{4}(5.6 \mathrm{~g}, 0.019 \mathrm{~mol})$ was added to the solution. After stirring the mixture for $3.5 \mathrm{~h}$ at $80^{\circ} \mathrm{C}$, the solid part was removed by filtration. The products were extracted with $\mathrm{CHCl}_{3}-\mathrm{aq} \mathrm{Na} \mathrm{CO}_{3}$. Removal of solvent from the organic layer after dying on $\mathrm{Na}_{2} \mathrm{SO}_{4}$ gave crude products which were purified by distillation under reduced pressure. Yield $8.37 \mathrm{~g}(37 \%)$. bp $128-135^{\circ} \mathrm{C} / 0.15$ mmHg. ${ }^{1} \mathrm{H}$ NMR $\left(400 \mathrm{MHz}, \mathrm{CDCl}_{3}, \mathrm{Me}_{4} \mathrm{Si}\right) \delta 7.25-$ $7.4(\mathrm{~m}, 11 \mathrm{H}$, aromatic $\mathrm{H}$ and vinyl $-\mathrm{CH}-), 5.10(\mathrm{~s}, 1 \mathrm{H}$, $-\mathrm{CH}-), 4.40$ and $4.90\left(\mathrm{~d}, 2 \mathrm{H}\right.$, vinyl $-\mathrm{CH}_{2}{ }^{-}$).

\section{Synthesis of VTPAc}

VTPAc was synthesized by a published $\operatorname{method}^{7}$ with modifications. In 500-ml flask, $\mathrm{Hg}\left(\mathrm{CH}_{3} \mathrm{CO}_{2}\right)_{2}(11 \mathrm{~g}$, $0.035 \mathrm{~mol})$ was dissolved in distilled water $(210 \mathrm{ml})$. Vinyl acetate $(3.2 \mathrm{ml}, 0.035 \mathrm{~mol})$ and $\mathrm{KCl}(2.6 \mathrm{~g}, 0.035 \mathrm{~mol})$ were added to the solution and the mixture was stirred for $24 \mathrm{~h}$ at ambient temperature. Water-insoluble product $\left(\mathrm{ClHgCH}_{2} \mathrm{CHO}^{8}\right)$ was collected with a centrifuge and dried under vacuum. Yield $6.4 \mathrm{~g}(66 \%)$. Triphenylacetyl chloride $(8.2 \mathrm{~g}, 0.027 \mathrm{~mol})$ prepared from the corresponding acid and $\mathrm{SOCl}_{2}$ and $\mathrm{ClHgCH}_{2} \mathrm{CHO}(9.7 \mathrm{~g}, 0.035 \mathrm{~mol})$ were placed in a $500-\mathrm{ml}$ flask equipped with a condenser under nitrogen atmosphere. Dry benzene $(180 \mathrm{ml})$ was introduced and the mixture was refluxed with stirring for $14 \mathrm{~h}$. Benzene was removed to give crude products after insoluble components were filtered off. The crude monomer was recrystallized from ether to give colorless crystals. Yield $3.9 \mathrm{~g}(47 \%)$. mp $114-115^{\circ} \mathrm{C} .{ }^{1} \mathrm{H}$ NMR $\left(400 \mathrm{MHz}, \mathrm{CDCl}_{3}, \mathrm{Me}_{4} \mathrm{Si}\right) \delta 7.2-7.6(\mathrm{~m}, 16 \mathrm{H}$, aromatic $\mathrm{H}$ and vinyl $-\mathrm{CH}-), 4.60$ and $4.80\left(\mathrm{~d}, 2 \mathrm{H}\right.$, vinyl $-\mathrm{CH}_{2}-$ ).

\section{Polymerization and Saponification of Polymers}

Polymerization was carried out under nitrogen atmosphere in a glass ampoule equipped with a three-way stop cock. The obtained polymers were converted to PVA by refluxing in a solution of $\mathrm{NaOH}(2 \mathrm{wt} \%)$ in a mixture of tetrahydrofuran (THF) and methanol. ${ }^{9}$ PVA was purified by precipitation in methanol and dried under vacuum. The triad tacticity of PVA was determined based on $-\mathrm{OH}$ signals in ${ }^{1} \mathrm{H}$ NMR spectra taken in dimethylsulfoxide- $d_{6} \cdot{ }^{10}$

\footnotetext{
Measurement

${ }^{1} \mathrm{H}$ NMR spectra were taken on a Varian Gemini 2000 spectrometer (400 MHz for ${ }^{1} \mathrm{H}$ measurement). GPC was performed with a Shodex System-21 GPC system equipped with a Shodex RI-71S detector using Shodex KF-803 and KF-806F columns connected in series (eluent, THF; flow rate, $1.0 \mathrm{ml} \mathrm{min}^{-1}$; temp, $40^{\circ} \mathrm{C}$ ).
} 


\section{RESULTS AND DISCUSSION}

\section{Homopolymerization of VDPAc and VTPAC}

The conditions and results of polymerization of VDPAc and VTPAc in toluene at $40^{\circ} \mathrm{C}$ are shown in Table I along with those for VAc and VPi. Under the used conditions, VDPAc gave a polymer with a higher syndiotacticity (triad $r r 42 \%$, diad $r 65 \%$ ) than VPi and VAc. Although VDPAc has been reported not to give a high polymer, ${ }^{6}$ in the present study we were able to obtain the polymers whose molecular weight was high enough for tacticity analysis as PVA. VTPAc gave only oligomeric products. This monomer may be too bulky to be polymerized.?

For the synthesis of poly(VDPAc) with higher syndiotacticity, various reaction conditions were applied to the polymerization (Table II). From the results of polymerization at different temperatures (runs $1-5$ ), a higher polymerization temperature was found to lead to a higher syndiotacticity. This temperature-tacticity relation is opposite to that observed for VPi polymerization in which a lower reaction temperature gives a higher syndiotactic specificity. ${ }^{11,1 \mathrm{~b}}$ Based on the Fordham plot $^{12}$ of the tacticity data of runs $1-5$ (Figure 1), the difference of activation enthalpy and that of activation entropy between isotactic and syndiotactic propagations were determined to be $\Delta H_{\mathrm{i}}^{\ddagger}-\Delta H_{\mathrm{s}}^{\ddagger}=-408 \mathrm{cal} \mathrm{mol}^{-1}$ and $\Delta S_{\mathrm{i}}^{\ddagger}-\Delta S_{\mathrm{s}}^{\ddagger}=-2.5 \mathrm{cal} \mathrm{deg}^{-1} \mathrm{~mol}^{-1}$, respectively, according to eq $^{12} 1$ :

Table I. Polymerization of vinyl esters using (iso- $\left.\mathrm{PrOCO}_{2}\right)_{2}$ in toluene at $40^{\circ} \mathrm{C}^{\mathrm{a}}$

\begin{tabular}{|c|c|c|c|c|c|c|}
\hline \multirow{2}{*}{ Run } & \multirow{2}{*}{ Monomer } & {$[\text { Monomer }]_{0}$} & Yield $^{b}$ & $M_{n}{ }^{\mathrm{c}}$ & \multirow[t]{2}{*}{$M_{w} / M_{n}^{\mathrm{c}}$} & \multirow{2}{*}{ Tacticity $^{\mathrm{d}}$} \\
\hline & & M & $\%$ & $\times 10^{3}$ & & \\
\hline 1 & VAc & 7.51 & 85 & 6.1 & 2.22 & $22 / 49 / 29$ \\
\hline 2 & VPi & 5.27 & 81 & 13.2 & 2.27 & $14 / 49 / 37$ \\
\hline 3 & VDPAc & 3.97 & 25 & 6.9 & 1.60 & $12 / 46 / 42$ \\
\hline $4^{e}$ & VTPAc & 0.86 & $18^{\mathrm{f}}$ & $1.0^{\mathrm{g}}$ & & \\
\hline
\end{tabular}

${ }^{\mathrm{a}}[$ Monomer $] /[$ initiator $]=50$. Time $24 \mathrm{~h} .{ }^{\mathrm{b}}$ Polymer was isolated by precipitation in hexane (runs 1 and 3 ) or by removing volatile components under high vacuum (run 2). $\quad{ }^{\mathrm{c}}$ Estimated by GPC using standard polystyrenes. ${ }^{\mathrm{d}}$ Estimated by ${ }^{1} \mathrm{H}$ NMR analysis in dimethylsulfoxide- $d_{6}$ of PVA derived from the original polymer. ${ }^{\mathrm{e}}$ In a mixture of tetrahydrofuran and toluene $(20: 1, \mathrm{vol} / \mathrm{vol}) .{ }^{\mathrm{f}}$ Estimated by ${ }^{1} \mathrm{H}$ NMR analysis of crude sample $\left(\mathrm{CDCl}_{3}\right)$. ${ }^{\mathrm{g}}$ Peak-top $M_{n}$ value.

$$
\ln \left(P_{\mathrm{i}} / P_{\mathrm{s}}\right)=\left(\Delta S_{\mathrm{i}}^{\ddagger}-\Delta S_{\mathrm{s}}^{\ddagger}\right) / R-\left(\Delta H_{\mathrm{i}}^{\ddagger}-\Delta H_{\mathrm{s}}^{\ddagger}\right) / R T
$$

where $P_{\mathrm{i}}$ and $P_{\mathrm{s}}$ are diad tacticity, $R$ is gas constant $\left(1.987 \mathrm{cal} \mathrm{deg}^{-1} \mathrm{~mol}^{-1}\right)$, and $T$ is polymerization temperature in $K$. Growing species in the VDPAc polymerization system may take a conformation leading to syndiotactic monomer addition for sterical reasons. Such conformation may be favored at a higher polymerization temperature resulting in higher syndiotactic specificity of polymerization. This assumption is supported by $\Delta H_{\mathrm{i}}^{\ddagger}-\Delta H_{\mathrm{s}}^{\ddagger}$ and $\Delta S_{\mathrm{i}}^{\ddagger}-\Delta S_{\mathrm{s}}^{\ddagger}$ obtained from Fordham plots.

Stereochemistry of the polymerization was also affected by solvent (runs 4, 6-9): alcoholic solvents gave higher syndiotacticities compared with hydrocarbon solvents. Monomer concentration slightly affected the stereochemistry of polymerization in methanol (runs 7 and 8). The polymerization in 2-propanol (run 9) gave the highest syndiotacticity in the present study (triad $r r$ $46 \%$, diad $r 67.5 \%$ ). Recently, PVA with a diad syndiotacticity of $69 \%$ was synthesized through polymerization of VPi in hexane at $-40^{\circ} \mathrm{C} .{ }^{13}$ Although the poly(VDPAc) prepared in the present study has a slightly lower syndiotacticity, our polymerization may be advantageous considering, as far as stereochemical control is concerned, that the syndiotactic specific VDPAc polymerization does not require extremely low reaction temperature.

\section{Copolymerization}

Copolymerizations of VDPAc with VAc and VPi were carried out and tacticity of the obtained copolymers was

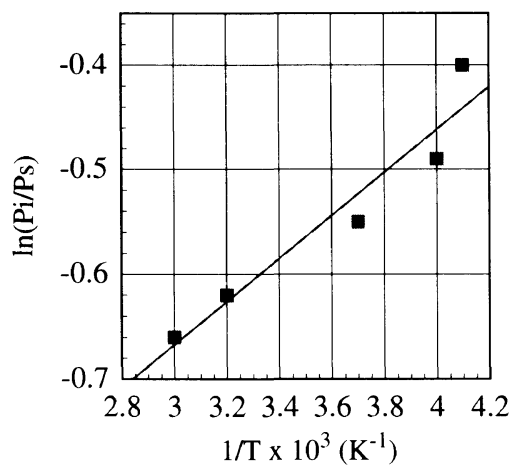

Figure 1. Fordham plots of the data of runs $1-5$ in Table II.

Table II. Polymerization of VDPAc under various conditions ${ }^{\mathrm{a}}$

\begin{tabular}{|c|c|c|c|c|c|c|c|c|}
\hline \multirow{2}{*}{ Run } & \multirow{2}{*}{ Initiator } & \multirow{2}{*}{ Solvent } & \multirow{2}{*}{$\frac{\text { Temp }}{{ }^{\circ} \mathrm{C}}$} & \multirow{2}{*}{$\frac{[\text { Monomer }]_{0}}{\mathbf{M}}$} & \multirow{2}{*}{$\frac{\text { Yield }^{\mathrm{b}}}{\%}$} & \multirow{2}{*}{$\frac{M_{n}^{\mathrm{c}}}{\times 10^{3}}$} & \multirow{2}{*}{$M_{w} / M_{n}^{\mathrm{c}}$} & \multirow{2}{*}{$\frac{\text { Tacticity }^{\mathrm{d}}}{\mathrm{mm} / \mathrm{mr} / \mathrm{rr}}$} \\
\hline & & & & & & & & \\
\hline 2. & BPO & None & -20 & 4.51 & 14 & 9.2 & 1.60 & $14 / 48 / 38$ \\
\hline 3 & BPO-DMA ${ }^{\mathrm{e}}$ & None & 0 & 4.37 & 24 & 9.4 & 1.72 & $13 / 47 / 40$ \\
\hline $4^{f}$ & (iso- $\left.\mathrm{PrOCO}{ }_{2}\right)_{2}$ & Toluene & 40 & 3.97 & 25 & 6.9 & 1.60 & $12 / 46 / 42$ \\
\hline 5 & AIBN & None & 60 & 4.31 & 27 & 6.9 & 1.50 & $12 / 44 / 44$ \\
\hline 6 & (iso- $\left.\mathrm{PrOCO}{ }_{2}\right)_{2}$ & Hexane & 40 & 2.37 & 50 & 5.1 & 1.56 & $14 / 44 / 42$ \\
\hline 7 & (iso-PrOCO$)_{2}$ & $\mathrm{MeOH}$ & 40 & 3.42 & 57 & 4.5 & 1.56 & $13 / 43 / 44$ \\
\hline 8 & (iso- $\left.\mathrm{PrOCO}{ }_{2}\right)_{2}$ & $\mathrm{MeOH}$ & 40 & 2.37 & 40 & 3.7 & 1.63 & $13 / 41 / 46$ \\
\hline 9 & (iso- $\left.\mathrm{PrOCO}_{2}\right)_{2}$ & 2-Propanol & 40 & 2.85 & 58 & 4.5 & 1.61 & $11 / 43 / 46$ \\
\hline
\end{tabular}

${ }^{\mathrm{a}}[\text { initiator }]_{0}=0.079-1.50 \mathrm{M}$. Time $4 \mathrm{~h}$ (run 1), $1 \mathrm{~h}$ (run 2), $24 \mathrm{~h}$ (runs 3, 4, 7, 9), $70 \mathrm{~h}$ (run 5), 48 h (runs 6,8 ). ${ }^{\mathrm{b}}$ Polymer was isolated by precipitation in hexane. ${ }^{\mathrm{c}}$ Estimated by GPC using standard polystyrenes. ${ }^{\mathrm{d}}$ Estimated by ${ }^{1} \mathrm{H}$ NMR analysis in dimethylsulfoxide- $d_{6}$ of PVA derived from the original polymer. ${ }^{\mathrm{e}}[\mathrm{BPO}]_{0} /[\mathrm{DMA}]_{0}=1 .{ }^{\mathrm{f}} \mathrm{Run} 3$ in Table $\mathrm{I}$. 
Free-Radical Polymerization of Bulky Vinyl Esters

Table III. Copolymerization of VDPAc $\left(\mathrm{M}_{1}\right)$ with VAc or VPi $\left(\mathrm{M}_{2}\right)$ using (iso-PrOCO$)_{2}$ in toluene at $40^{\circ} \mathrm{C}^{\mathrm{a}}$

\begin{tabular}{|c|c|c|c|c|c|c|c|}
\hline \multirow{2}{*}{ Run } & \multirow{2}{*}{$\mathrm{M}_{2}$} & \multirow{2}{*}{$\begin{array}{l}\mathrm{M}_{1} / \mathrm{M}_{2} \\
\text { in feed }\end{array}$} & Yield $^{\text {b }}$ & \multirow{2}{*}{$\begin{array}{c}\mathrm{M}_{1} / \mathrm{M}_{2} \\
\text { in remaining } \\
\text { monomer }\end{array}$} & \multirow{2}{*}{$\begin{array}{l}M_{n}^{\mathrm{c}} \\
\times 10^{3}\end{array}$} & \multirow{2}{*}{$M_{w} / M_{n}{ }^{\mathrm{c}}$} & \multirow{2}{*}{$\begin{array}{l}\text { Tacticity }^{\mathrm{d}} \\
m m / m r / r r\end{array}$} \\
\hline & & & $\%$ & & & & \\
\hline 1 & VAc & $90 / 10$ & 25 & $89 / 11$ & 7.0 & 1.58 & $15 / 45 / 40$ \\
\hline 2 & VAc & $49 / 51$ & 32 & $47 / 53$ & 7.4 & 1.62 & $17 / 47 / 36$ \\
\hline 3 & VAc & $30 / 70$ & 46 & $28 / 72$ & 8.2 & 1.75 & $17 / 49 / 34$ \\
\hline 4 & VAc & $10 / 90$ & 69 & $8 / 92$ & 9.3 & 1.94 & $20 / 48 / 32$ \\
\hline 5 & $\mathrm{VPi}$ & $80 / 20$ & 20 & $81 / 19$ & 7.6 & 1.65 & $14 / 47 / 39$ \\
\hline 6 & $\mathrm{VPi}$ & $50 / 50$ & 29 & $52 / 48$ & 8.8 & 1.71 & $15 / 49 / 36$ \\
\hline 7 & VPi & $20 / 80$ & $41^{\mathrm{e}}$ & $22 / 78$ & 11.8 & 1.85 & $15 / 49 / 36$ \\
\hline
\end{tabular}

${ }^{\mathrm{a}}[\text { Monomer }]_{0}=3.97-7.51 \mathrm{M}$. [Initiator $]_{0}=0.079-0.15 \mathrm{M}$. Time $24 \mathrm{~h}$. See runs $1-3$ in Table I for the results of homopolymerization of $\mathrm{M}_{1}$ or $\mathrm{M}_{2}$. ${ }^{\mathrm{b}}$ Polymer was isolated by precipitation in hexane. ${ }^{\mathrm{c}}$ Estimated by GPC using standard polystyrenes. ${ }^{\mathrm{d}}$ Estimated by ${ }^{1} \mathrm{H}$ NMR analysis in dimethylsulfoxide- $d_{6}$ of PVA derived from the original polymer. ${ }^{e}$ Polymer was isolated by precipitation in $\mathrm{MeOH}-\mathrm{H}_{2} \mathrm{O}(1: 1, \mathrm{vol} / \mathrm{vol})$.

investigated (Table III). The compositions $\left(\mathrm{M}_{1} / \mathrm{M}_{2}\right)$ of remaining monomers were quite similar to those of fed monomers even at the rather high polymer yield, suggesting monomer reactivity ratios of $r_{1} \approx r_{2} \approx 1$ for the both copolymerizations. As for the stereochemistry of copolymerization, syndiotacticity of the obtained copolymers decreased with an increase in the content of VAc or VPi unit in the polymer chain and no particular improvement in stereospecificity was observed by the copolymerization. Copolymerization of VTPAc with VAc was also performed but only oligomeric products were obtained.

\section{CONCLUSION}

Free-radial polymerization of VDPAc exhibits higher syndiotactic specificity than polymerization of VPi.

Acknowledgments. This work was partly supported by NEDO for the project on Technology for Novel High-Functional Materials in Industrial Science and Technology Frontier Program, AIST.

\section{REFERENCES AND NOTES}

1. For reviews: (a) C. A. Finch, Ed., "Polyvinyl Alcohol Developments," Wiley, Chichester, 1992, (b) "PVA no Sekai (The World of PVA)," Kobunshi Kankokai, Kyoto, 1992.

2. K. Imai, T. Shiomi, N. Oda, and H. Otsuka, J. Polym. Sci., Part $A, 24,3225$ (1986).

3. S. Matsuzawa, K. Yamaura, and H. Noguchi, Makromol. Chem., 168, 27 (1973).

4. R. Fukae, T. Yamamoto, Y. Fujita, N. Kawatsuki, O. Sangen, and M. Kamachi, Polym. J., 27, 1257 (1995).

5. U. Kador and P. Mehnert, Makromol. Chem., 144, 29 (1971).

6. H. Lüssi, Kunststoffe Plastics, 3, 156 (1956).

7. J. Nishino, K. O, M. Kishida, T. Saburi, Z. Ishikawa, and Y. Sakaguchi, Kobunshi Kagaku (Japan), 22, 546 (1965).

8. A. N. Nesmeyanov, I. F. Lutsenko, and Z. M. Tumanova, Izvest. Akad. Nauk S.S S.R., Otdel Khim. Nauk, 601 (1949) [Chem. Abstr., 44, 7225 (1950)].

9. T. Otsu, A. Matsumoto, K. Endo, and H. Kataoka, Mem. Fac. Eng., Osaka City Univ., 29, 161 (1988).

10. T. Moritani, I. Kuruma, K. Shibatani, and Y. Fujiwara, Macromolecules, 5, 577 (1972).

11. S. Nozakura, M. Sumi, M. Uoi, T. Okamoto, and S. Murahashi, J. Polym. Sci., Chem. Ed., 11, 279 (1973).

12. J. W. L. Fordham, J. Polym. Sci., 39, 321 (1959).

13. R. Fukae, T. Yamamoto, Y. Fujita, N. Kawatsuki, O. Sangen, and M. Kamachi, Polym. J., 29, 293 (1997). 